\title{
A Two-Step Molecular Detection Method for Pyrenophora tritici-repentis Isolates Insensitive to Qol Fungicides
}

Jaimin S. Patel and Steven W. Meinhardt, Department of Plant Pathology, North Dakota State University, NDSU Department 7660, P.O. Box 6050, Fargo, ND 58108; Helge Sierotzki, Syngenta Crop Protection, Research Biology, 4332 Stein, Switzerland; Gerd Stammler, BASF Aktiengesellschaft, 67117 Limburgerhof, Germany; and Neil C. Gudmestad and Tika B. Adhikari, Department of Plant Pathology, North Dakota State University, NDSU Department 7660, P.O. Box 6050, Fargo, ND 58108

\begin{abstract}
Patel, J. S., Meinhardt, S. W., Sierotzki, H., Stammler, G., Gudmestad, N. C., and Adhikari, T. B. 2011. A two-step molecular detection method for Pyrenophora tritici-repentis isolates insensitive to QoI fungicides. Plant Dis. 95:1558-1564.

Tan spot, caused by Pyrenophora tritici-repentis, is an important disease of wheat worldwide. To manage tan spot, quinone outside inhibitor (QoI) fungicides such as azoxystrobin and pyraclostrobin have been applied in many countries. QoI fungicides target the cytochrome $b$ (cyt $b$ ) site in complex III of mitochondria and, thus, pose a serious risk for resistance development. The resistance mechanism to QoI fungicides is mainly due to point mutations in the cyt $b$ gene. The objective of this study was to develop a molecular detection method for the four currently known mutations responsible for shifts in sensitivity toward QoI fungicides in $P$. tritici-repentis. Twelve specific primers were designed based on sequences from the National Center for Biotechnology Information accessions AAXI01000704 and DQ919068 and used to generate a fragment of the cyt $b$ gene which possesses four known singlenucleotide polymorphisms (SNPs). These mutant clones served as positive controls because QoI-insensitive and -reduced-sensitive isolates of $P$. tritici-repentis have not yet been reported in the United States. The partial cyt $b$ gene clones were sequenced to identify the SNPs at sites G143A and F129L. Genomic DNA of the mutated partial

cyt $b$ gene clones and the European QoI-insensitive and -reducedsensitive isolates of $P$. tritici-repentis possessing G143A (GCT) and F129L (TTA, TTG, and CTC) mutations were amplified by polymerase chain reaction (PCR) using two specific primer pairs and were further digested with three specific restriction enzymes (BsaJI, Fnu4HI, and $M n l I)$. The results of the digested PCR product from genomic DNA of known QoI-insensitive and -reduced-sensitive isolates of $P$. triticirepentis had DNA bands consistent with the mutation GCT at G143A and the mutations TTA, TTG, and CTC at F129L. The amplified region at the F129 site also had $99 \%$ sequence similarity with $P$. teres, the net blotch pathogen of barley. To validate mutations, we further tested two isolates of $P$. teres known to have reduced sensitivity to QoI fungicides possessing the mutations TTA and CTC at F129L. After PCR amplification and restriction digestion, DNA bands identical to those observed for the partial cyt $b$ mutant clones were detected. These results suggest that this newly developed two-step molecular detection method is rapid, robust, and specific to monitor QoI-insensitive and -reducedsensitive isolates of $P$. tritici-repentis.
\end{abstract}

Tan spot, caused by Pyrenophora tritici-repentis, is a widespread disease in wheat-growing regions in the world. The disease can cause yield losses of up to $50 \%$ in favorable weather conditions $(25,28)$. Only a few moderately resistant wheat cultivars are available to manage the disease (24). Thus, the application of foliar fungicides is frequently used by growers to manage $\tan$ spot. Although some of the fungicides (FRAC code M1 and M3) registered on wheat have been considered to have low resistance risk (10), fungicides with a single-site mode of action are generally more prone to develop resistance than multiple-site modes of action.

The quinone outside inhibitor (QoI) fungicides are a relatively new class of fungicide, with azoxystrobin receiving Environmental Plant Protection registration in 1997. Kresoxim-methyl was registered in 1998, trifloxystrobin followed in 1999, and pyraclostrobin received registration in 2003 in the United States. Soon after these fungicides were released for commercial use, resistance was reported with certain fungi in Asia and Europe $(15,29,30,34)$. More importantly, QoI fungicides have a site-specific mode of action (mitochondrial respiration inhibition resulting in prevention of

Corresponding author: T. B. Adhikari,

E-mail: tika.adhikari@ndsu.edu and tadhikari31@yahoo.com

Current address of Jaimin S. Patel: University of Florida, IFAS, Mid-Florida Research \& Education Center, Apopka 32703-8504.

Accepted for publication 14 July 2011.

doi:10.1094/PDIS-05-11-0413

(C) 2011 The American Phytopathological Society spore germination and mycelial growth) and therefore, they have a high risk of developing resistance $(29,33)$.

QoI fungicides such as azoxystrobin and pyraclostrobin are recommended for managing tan spot. Although QoI fungicides were effective during all stages, the stage of fungal development most sensitive to these fungicides was during spore germination $(3,33)$. Insensitivity or reduced sensitivity toward QoI fungicides have been reported in many plant pathogens such as Blumeria graminis, Alternaria alternata, A. solani, Colletotrichum graminicola, Magnaporthe grisea, Ascochyta rabiei, Monilinia fructicola, and $P$. teres $(2,5,7,11,18,23,29,34,36)$. The QoI-insensitive and -reducedsensitive isolates of these fungi have single-nucleotide polymorphism (SNP) in the cyt $b$ gene $(7,18,23,29)$. The mutations involved in conveying resistance could be at either the G143 or F129 location. Populations of the fungi carrying these mutations can lead to less disease control when QoI fungicides are used without mixing partners (23). Thus, monitoring isolates of plant-pathogenic fungi insensitive to QoI fungicides is necessary to implement management strategies.

Rapid molecular detection methods allow monitoring of plant pathogens on a regular basis and should be more sensitive and faster than conventional methods such as spore germination assays. Some examples of new molecular detection techniques include the melanin biosynthesis inhibitor insensitive isolates of Magnaporthe grisea using primer-introduced restriction enzyme analysis in the scytalone dehydratase gene (16). Similarly, insensitive isolates of Cadobotryum dendroids, causal agent of cobweb disease of edible mushroom Agaricus bisporus, to methyl benzimidazole carbamate (MBC) were detected using species-specific primers followed by a restriction enzyme (21). Identification of Botrytis cinerea isolates insensitive to $\mathrm{MBC}$ was identified using the two-step polymerase chain reaction (PCR) method (20). The QoI-insensitive cucumber 
powdery mildew pathogen Podosphaera fusca has been identified using PCR followed by treatment with a selected restriction enzyme (15). A real-time PCR assay was used to detect melting point differences in the SNPs that differentiate sensitive and F129L mutants of Alternaria solani (22). A PCR-based restriction fragment length polymorphism (RFLP) analysis was used to detect the substitution of nucleotide at F129L position in M. grisea (4).

Current assays for detecting a change in QoI-sensitive isolates of Pyrenophora tritici-repentis include culture media amended with fungicides and real-time PCR (29). Although these methods have been recommended and used in the laboratory, most of these methods are either time consuming or expensive for field applications. Additionally, tan spot is a destructive disease of wheat in the United States, and a robust and specific method for detecting a change in the QoI-insensitive or -reduced-sensitive isolates of $P$. tritici-repentis is still lacking. Therefore, these factors prompted us to search for an alternative detection method in P. tritici-repentis. For laboratories with access to a real-time PCR machine, it could be less expensive to perform real-time PCR than conventional PCR plus restriction digestion. The technique described here would be useful for laboratories with no access to real-time PCR.

The main objective of this study was to develop a two-step molecular diagnostic method (PCR followed by restriction enzyme digestion) to identify the four known SNPs, one at the G143A and three at the F129L position in the cyt $b$ gene of $P$. tritici-repentis. In this method, we created mutant clones in order to serve as controls because no QoI-insensitive or -reduced-sensitive isolates of $P$. tritici-repentis have been found in the United States. This rapid and specific detection method will be useful for monitoring QoI-insensitive and -reduced-sensitive isolates of $P$. tritici-repentis.

\section{Materials and Methods}

DNA isolation. Genomic DNA was extracted from P. tritici-repentis isolate Pti2 from South Dakota. A cellophane membrane was placed on V8 potato dextrose agar (PDA; $150 \mathrm{ml}$ of V8 juice, $10 \mathrm{~g}$ of Difco PDA, $3 \mathrm{~g}$ of $\mathrm{CaCO}_{3}, 10 \mathrm{~g}$ of Difco bacto agar, and $850 \mathrm{ml}$ of distilled water) medium upon which a mycelial plug of $5 \mathrm{~mm}$ in diameter of isolate Pti2 was placed and incubated for 6 days at $21^{\circ} \mathrm{C}$ in the dark. Mycelia were collected by gently scraping off cellophane membrane, lyophilized, and ground into fine powder using two metal beads in a 2-ml Eppendorf tube. Genomic DNA was extracted as described previously (1). Genomic DNA of $17 P$. tritici-repentis isolates obtained from Syngenta, Switzerland was analyzed in this study. To validate our assay, genomic DNA of two isolates (Pt1555 and Pt1541) of P. teres received from BASF, Germany was also included in this study.
Sensitivity tests to QoI fungicides. A set of 17 P. tritici-repentis isolates were previously characterized for QoI sensitivity and the presence or absence of cyt $b$ gene mutations (29). The sensitivity of isolates Pt1541 and Pt1555 of $P$. teres with the F129L mutation was determined by a microtiter assay using YBA medium (10 $\mathrm{g}$ of yeast extract, $10 \mathrm{~g}$ of Bacto peptone, and $20 \mathrm{~g}$ of sodium acetate in 1 liter of sterile deionized water) at $0,0.0003,0.001,0003,001$, $0.03,0.1$, or $0.3 \mathrm{mg} /$ liter of pyraclostrobin. Per well, 200 spores and $100 \mu \mathrm{l}$ of nutrient solution were used and the plates were incubated for 5 days at $18^{\circ} \mathrm{C}$ in dark. Fungal growth was evaluated with a photometer and $50 \%$ effective concentration $\left(\mathrm{EC}_{50}\right)$ values were calculated by Probit analysis.

Primer design. At least four SNPs have been found to be responsible for a change in sensitivity to the QoI fungicides (29). In particular, one SNP, GCT, was responsible for the G143A mutation and any one of three SNPs (TTA, TTG, and CTC) was responsible for the F129L mutation (29). To detect the four SNPs in the cyt $b$ gene, primers were designed from sequences of the cyt $b$ gene in complex III obtained from fragments of mitochondrial whole-genome shotgun sequence (the National Center for Biotechnology Information [NCBI] accession AAXI01000704) and partial mitochondrial coding sequence of $P$. tritici-repentis (NCBI accession DQ919068). One fragment of the cyt $b$ gene (NCBI accession DQ919068) with a length of 296 bp (from 2,490 to 2,785 bp) covers the G143 site and another fragment of the cyt $b$ gene (NCBI accession AAXI01000704) with a length of 584 bp (from 15,921 to $16,504 \mathrm{bp}$ ) covers the F129 site. Four different primers were designed to generate a mutant clone for G143A site by replacing a single nucleotide (Table 1). Among those four primers, only two primers (FG143 and RFG143) were used to detect a SNP at G143A site in field $P$. tritici-repentis isolates. All four primers were used to create a mutant clone for G143A site by replacing a single nucleotide (Table 1). Mutations at the F129L location have three possible SNPs (TTA, TTG, and CTC) which change phenylalanine into leucine. Similarly, eight different primers were designed to create mutant clones for F129L by replacing a desired single nucleotide (Table 2). Among those eight primers, only two primers (FF129 and RF129) were used to detect SNPs in field isolates of $P$. tritici-repentis (Table 2). All primers were synthesized by Integrated DNA Technologies, Coralville, IA.

Amplification of partial cyt $b$ fragments with SNPs resulting in the G143A and F129L mutations. The G143 codon GGT was changed to GCT through PCR using two different pairs of primers, FG143-MRG143 and MFG143-RG143 (Table 1). Each pair amplified a separate fragment. However, primers were designed in such a way that part of the amplified fragments would overlap

Table 1. Four primers used to amplify the region surrounding G143A and to generate mutant clones

\begin{tabular}{lll}
\hline Primer name & \multicolumn{1}{c}{ Sequence $\left(\mathbf{5}^{\prime} \rightarrow \mathbf{3}^{\prime}\right)^{\mathbf{a}}$} & \multicolumn{1}{c}{ Feature $^{\mathbf{b}}$} \\
\hline FG143 & 5' GCA GCT TTA GCC CTT GGT AA 3' & PCR product covering G143 site \\
MFG143 & 5' GTC ATT ATG AGC TGC TAC AGT TAA AAA GG 3' & Replaced G $\rightarrow$ C at G143 position \\
MRG143 & 5' CTT TTT AAC TGT AGC AGC TCA TAA TGA CAT 3' & Replaced C $\rightarrow$ G at C143 position \\
RG143 & 5' CTG CGC TAT TTT TAA TAT AGG TTC CTG 3' & PCR product covering G143 site \\
\hline
\end{tabular}

a A bold letter in shaded codon is responsible to change G143 to G143A in cyt $b$ gene of Pyrenophora tritici-repentis.

${ }^{\mathrm{b}} \mathrm{PCR}=$ polymerase chain reaction.

Table 2. Eight primers used to amplify the region surrounding F129L and to generate mutant clones for three possible single-nucleotide polymorphisms

\begin{tabular}{lll}
\hline Primer name & \multicolumn{1}{c}{ Sequence $\left(\mathbf{5}^{\prime} \rightarrow \mathbf{3}^{\prime}\right)^{\mathbf{a}}$} & \multicolumn{1}{c}{ Feature $^{\mathbf{b}}$} \\
\hline FF129 & 5' AGG GTA TCT TTA ACT TGA CAC CAA TAA TT 3' & Amplified PCR product covering F129 site \\
MFTTA & 5' TTA GAC AGC CTT ACT GGG TTA CC 3' & Replaced C $\rightarrow$ A at F129 site \\
MRTTA & 5' G GTA ACC CAG TAA GGC TGT CTA AG 3' & Replaced G $\rightarrow$ T at F129 site \\
MFTTG & 5' TTA GAC AGC CTT GCT GGG TTA C 3' & Replaced C $\rightarrow$ G at F129 site \\
MRTTG & 5' G GTA ACC CAG CAA GGC TGT CTA AG 3' & Replaced G $\rightarrow$ C at F129 site \\
MFCTC & 5' GAC AGC CCT CCT GGG TTA C 3' & Replaced T $\rightarrow$ C at F129 site \\
MRCTC & 5' GTA ACC CAG GAG GGC TGT CTA AG 3' & Replaced A $\rightarrow$ G at F129 site \\
RF129 & 5' TTC CAA GAC TAT TTG AGG AAC TAC TTG 3' & Amplified PCR product covering F129 site \\
\hline
\end{tabular}

\footnotetext{
${ }^{a}$ A bold letter in shaded codon is responsible to change F129 to F129L in cyt $b$ gene of Pyrenophora tritici-repentis
}

${ }^{\mathrm{b}} \mathrm{PCR}=$ polymerase chain reaction. 
$(13,14)$, where artificial replacement of a nucleotide would occur at position G143A (Table 1). PCR reagents and solutions were purchased from Promega Corporation (Madison, WI). The PCR mixture was prepared by adding $9.75 \mu \mathrm{l}$ of $\mathrm{H}_{2} \mathrm{O}, 4.0 \mu \mathrm{l}$ of $5 \times$ buffer, 1.5 $\mu \mathrm{l}$ of $\mathrm{MgCl}_{2}, 0.5 \mu \mathrm{l}$ of dNTP, $3.0 \mu \mathrm{l}$ of primer $(1.5 \mu \mathrm{l}$ each of forward and reverse primer), $0.25 \mu \mathrm{l}$ of Taq polymerase, and $1.0 \mu \mathrm{l}$ of template DNA $(10 \mathrm{ng} / \mu \mathrm{l})$. All PCR reactions were run in a PTC100 Peltier Thermal Cycler (MJ Research, Waltham, MA). The thermal cycler conditions were set to 40 cycles of $95^{\circ} \mathrm{C}$ for $30 \mathrm{~s}$, $58^{\circ} \mathrm{C}$ for $20 \mathrm{~s}$, and $72^{\circ} \mathrm{C}$ for $30 \mathrm{~s}$. Upon successful amplification of two partial cyt $b$ fragments, each was cut from the agarose gel and purified using the QIAquick Gel Extraction Kit (Qiagen, Chatsworth, CA). The purified DNA was adjusted to $5 \mathrm{ng} / \mu \mathrm{l}$ by adding Tris-EDTA (TE; $1.0 \mathrm{ml}$ of $1 \mathrm{M}$ Tris, $0.2 \mathrm{ml}$ of $0.5 \mathrm{M}$ EDTA, and sterile distilled water to make a total volume of $100 \mathrm{ml}$ ) buffer adjusted to $\mathrm{pH}$ 8.0. A short PCR was run using the two purified PCR fragments as template DNA and as primers to amplify a 296bp fragment of the cyt $b$ gene having the GCT codon at G143A position. The same PCR program was performed as mentioned above with 10 repeated cycles instead of 40 cycles. After 10 PCR cycles, $1.5 \mu$ of each forward primer FG143 and reverse primer RG143 was added to the same PCR tubes and the same PCR program was run with 40 cycles to amplify 296 bp of partial cyt $b$ gene with the changed G143A site.

The TTC codon was changed to TTA, TTG, and CTC at the F129 site using the following six primer pairs to replace specific nucleotide: pair 1, FF129 and MRTTA; pair 2, MFTTA and RF129; pair 3, FF129 and MRTTG; pair 4, MFTTG and RF129; pair 5, FF129 and MRCTC; and pair 6, MFCTC and RF129 (Table 2). The amplified products from primer pairs 1 and 2 overlapped with a nucleotide changed from cytosine to adenine (TTC to TTA) within the overlap. Similarly, primer pairs 3 and 4 changed cytosine to glycine (TTC to TTG) and primer pairs 5 and 6 changed thymine to cytosine (TTC to CTC) at F129. Each of the amplified fragments was cut from the agarose gel and purified using the QIAquick Gel Extraction Kit (Qiagen) and was adjusted to $5 \mathrm{ng} / \mu \mathrm{l}$ by adding TE buffer. A short PCR was run using the two PCR fragments as template and primers to amplify a 584-bp fragment of the cyt $b$ gene having a modified codon at F129L position with the same PCR program as mentioned above with 10 repeated cycles. For example, amplified products from the primer pair FF129 and
MFTTA and pair MFTTA and RF129 served as templates and primers in a short PCR. A second PCR with 40 repeated cycles were run with end primers added to generate copies of a 584-bp partial cyt $b$ gene covering the F129L codon. All second PCRs used the same PCR program as mentioned previously, except there was a $62^{\circ} \mathrm{C}$ annealing temperature for amplifying a partial cyt $b$ gene covering the CTC (F129L) codon.

Gel electrophoresis. Two concentrations (1.5 and 2\%) agarose gels in $0.5 \times$ Tris-borate-EDTA ( $90 \mathrm{mM}$ Tris, $90 \mathrm{mM}$ boric acid, and $0.1 \mathrm{mM}$ EDTA) were used to separate the PCR products and stained with ethidium bromide. In most experiments, $1.5 \%$ agarose gel was used, whereas $2 \%$ agarose gel was used only to diagnose the GCT codon at the G143A site. Photographs were taken in a Fluorochem 2200 Image system (Alpha Innotech Corp., San Leandro, CA).

Partial cyt $b$ gene clone sequencing and restriction digestion. The amplified PCR products were ligated to the pGEM-T Easy Vector (catalog number A1360; Promega Corporation) and transformed into the competent Escherichia coli cells. The transformed $E$. coli cells were selected on Luria-Bertani agar plates containing ampicillin, 5-bromo-4-chloro-3-indolyl- $\beta$ - $\mathrm{D}$-galactoside, and isopropylthio- $\beta$-D-galactoside (26). Plasmids from the transformed $E$. coli cells were purified using the PureYield Plasmid Miniprep System (catalog number A1220; Promega Corporation). Purified plasmids were used as a template in PCR to amplify a portion of the cyt $b$ gene using the end forward and reverse primers. PCR copies were sent to Molecular Cloning Laboratories (San Francisco) for sequencing the amplified fragment of the plasmid.

After sequencing, BioEdit software (http://www.mbio.ncsu.edu/ BioEdit/BioEdit.html) was used to align the DNA sequences to NCBI accessions DQ919068 and AAXI01000704 to determine if the single nucleotide was successfully replaced in the G143 and F129 codons. The PCR products were also digested using three different restriction enzymes: Fnu4HI, BsaJI, and MnlI (New England Biolabs Inc., MA) according to the manufacturer's protocol to identify each mutation (GTC, TTA or TTG, and CTC). Restriction enzyme Fnu4HI detected the GTC mutation, MnlI detected the CTC mutation, and BsaJI detected both the TTA and TTG mutations.

\section{Results}

Sensitivity tests to QoI fungicides. The set of 17 isolates of $P$. tritici-repentis (Table 3) had $\mathrm{EC}_{50}$ values of 0.04 to $100 \mathrm{mg} / \mathrm{liter}$.

Table 3. Wild-type and mutant isolates of Pyrenophora tritici-repentis and P. teres with known nucleotide substitution at the G143A and F129L locations

\begin{tabular}{|c|c|c|c|c|c|}
\hline \multirow[b]{2}{*}{ Isolates } & \multirow[b]{2}{*}{ Wild type } & \multicolumn{3}{|c|}{ Nucleotide substitution $^{\mathrm{a}}$} & \multirow[b]{2}{*}{$\mathrm{EC}_{50}(\mathrm{mg} / \mathrm{liter})^{\mathrm{b}}$} \\
\hline & & G143A (GCT) & F129L (TTA or TTG) & F129L (CTC) & \\
\hline 06DTR D005.4 & Yes & No & No & No & 0.04 \\
\hline 06DTR D007.1 & Yes & No & No & No & 0.1 \\
\hline 06DTR D049.1 & Yes & No & No & No & 0.1 \\
\hline 06DTR D013.3 & Yes & No & No & No & 0.1 \\
\hline 06DTR D040.5 & Yes & No & No & No & 0.1 \\
\hline 06DTR D036.3 & Yes & No & No & No & 0.1 \\
\hline 05DTR D003.1 & Yes & No & No & No & 0.3 \\
\hline 04DTR DK010.2 & No & No & Yes & No & 0.4 \\
\hline 06DTR D036.4c & No & No & No & No & 1.6 \\
\hline 06DTR D005.3 & Yes & No & No & No & 1.9 \\
\hline 06DTR D021.1 & No & No & No & Yes & 3.1 \\
\hline 06DTR D014.2 & No & No & No & No & 3.4 \\
\hline 06DTR D049.2 & No & Yes & No & No & 4.8 \\
\hline 06DTR D039.2 & No & Yes & No & No & 5.6 \\
\hline 06DTR D002.1 & No & Yes & No & No & 100 \\
\hline 06DTR D004.2 & No & Yes & No & No & 100 \\
\hline 06DTR D023.5 & No & No & No & Yes & 100 \\
\hline Pt1555 & No & No & Yes & No & $0.005^{\mathrm{f}}$ \\
\hline Pt1541e & No & No & No & Yes & $0.007^{\mathrm{f}}$ \\
\hline
\end{tabular}

${ }^{a}$ Responsible codon for mutation is described in parentheses.

${ }^{\mathrm{b}} \mathrm{EC}_{50}$ (50\% effective concentration) values for azoxystrobin and isolates of P. tritici-repentis.

${ }^{\mathrm{c}}$ Isolate with reduced sensitivity without known responsible codons (GCT at G143A; TTA, TTG, and CTC at F129L; and AGG at G137R) in the cyt $b$ gene.

${ }^{\mathrm{d}}$ Isolate with codon AGG at G137R in the cyt $b$ gene.

e P. teres isolate.

${ }^{\mathrm{f}} \mathrm{EC}_{50}$ value for pyraclostrobin and $P$. teres isolates. 
Among them, four isolates with the GCT codon at G143A (Table 3) had the highest $\mathrm{EC}_{50}$ values (29). One isolate (04 DTR DK010.2) of $P$. tritici-repentis had either the TTA or TTG codon at F129L (Table 3) and an $\mathrm{EC}_{50}$ value of $0.4 \mathrm{mg} / \mathrm{liter}$. Two isolates had the CTC codon at F129L (Table 3), among which isolate 06DTR D021.1 had an $\mathrm{EC}_{50}$ value of $3.1 \mathrm{mg} / \mathrm{liter}$ and isolate 06 DTR D023.5 had an $\mathrm{EC}_{50}$ value of $100 \mathrm{mg} /$ liter (29). The remaining 10 isolates of $P$. tritici-repentis had $\mathrm{EC}_{50}$ values of $<3.4$ $\mathrm{mg} /$ liter. Sensitivity analysis of two isolates Pt1541 and Pt1555 of $P$. teres to pyraclostrobin showed $\mathrm{EC}_{50}$ values 0.007 and 0.005 $\mathrm{mg} /$ liter indicating low resistance factors $\left(\mathrm{EC}_{50}\right.$ isolate/EC $\mathrm{EC}_{50}$ wild type) of 5 to 7 .

Sequencing and restriction digestion of wild-type and mutant partial cyt $\boldsymbol{b}$ clones. Sequence analysis revealed that guanine was replaced with cytosine (GGT to GCT) in the G143 codon in transformed E. coli plasmids. Among the three transformed E. coli plasmids at the F129 position, cytosine was replaced with adenine (TTC to TTA) in one mutant clone and guanine (TTC to TTG) in a second mutant clone at position F129. Single nucleotide replacement from TTC to CTC in the F129 codon was also confirmed in a third mutant clone. Amplification of the partial cyt $b$ gene with one mutation at position G143A and three mutations at position F129L showed distinct fragments upon restriction digestion when compared with the wild-type sequences (Fig. 1). Digested wild-type genomic DNA (GGT at G143) showed two fragments of 165 and $131 \mathrm{bp}$ and digested mutant DNA (GCT at G143A) showed 165 and 103 bp when digested with Fnu4HI. In the case of the three different SNPs at F129, two SNPs (TTA and TTG) had identical DNA band patterns when treated with BsaJI (Fig. 1). Digested wild-type DNA (TTC at F129) showed DNA bands of 418 and 166 bp whereas the digested mutant (TTA and TTG at F129L) DNA showed only a 584-bp DNA band. The digested wild-type sequence (TTC at F129) appeared with 538 bp, whereas the sequence with a codon change from TTC to CTC showed distinct signals of 425 and 114 bp in a $1.5 \%$ agarose gel when treated with $M n l$ I (Fig. 1).

Testing QoI-sensitive, -reduced-sensitive, and -insensitive isolates of $\boldsymbol{P}$. tritici-repentis. We examined the 17 isolates of $P$. triticirepentis for the presence of codons at $\mathrm{G} 143$ and F129 responsible for the sensitive or insensitive response (Table 3). Of the 17 genomic DNA samples analyzed, 7 samples had a codon change at either G143A or F129L (Table 3). Digested DNA of the four isolates had a DNA band identical to the control containing the GCT codon (G143A mutation; Fig. 2A), one isolate was identical to the controls containing the TTA and TTG SNPs at F129L (Fig. 2B), and two isolates had DNA bands identical to the control, with the CTC mutation at F129L (Fig. 2C). The remaining isolates had DNA bands identical to the controls and had no mutations (Fig. 2A-C).

Testing QoI-reduced-sensitive isolates of P. teres. Analysis of genomic DNA of two isolates of $P$. teres showed that the isolate Pt1555 had a DNA band identical to control, with the TTA and TTG SNPs with a single DNA band at 584 bp (Fig. 2B), and isolate Pt1541 had a DNA band identical to the control, with the CTC SNP with 425 and 114 bp (Fig. 2C).

\section{Discussion}

Traditionally, evaluation of fungicide resistance is performed by adding different concentrations of fungicides in the culture media and determining the spore germination rate $(5,6,8,12,15,17,18$, 29,30,36). This method does not require molecular equipment but is time consuming. In this study, we used a set of specific primers for PCR amplification of the region most known to have resistance codons, followed by restriction enzyme digestion, providing a rapid and specific molecular detection method to monitor QoIinsensitive and -reduced-sensitive isolates of $P$. tritici-repentis.

Several primers have been used to identify the structure of the cyt $b$ gene of $P$. tritici-repentis and $P$. teres previously (29). This

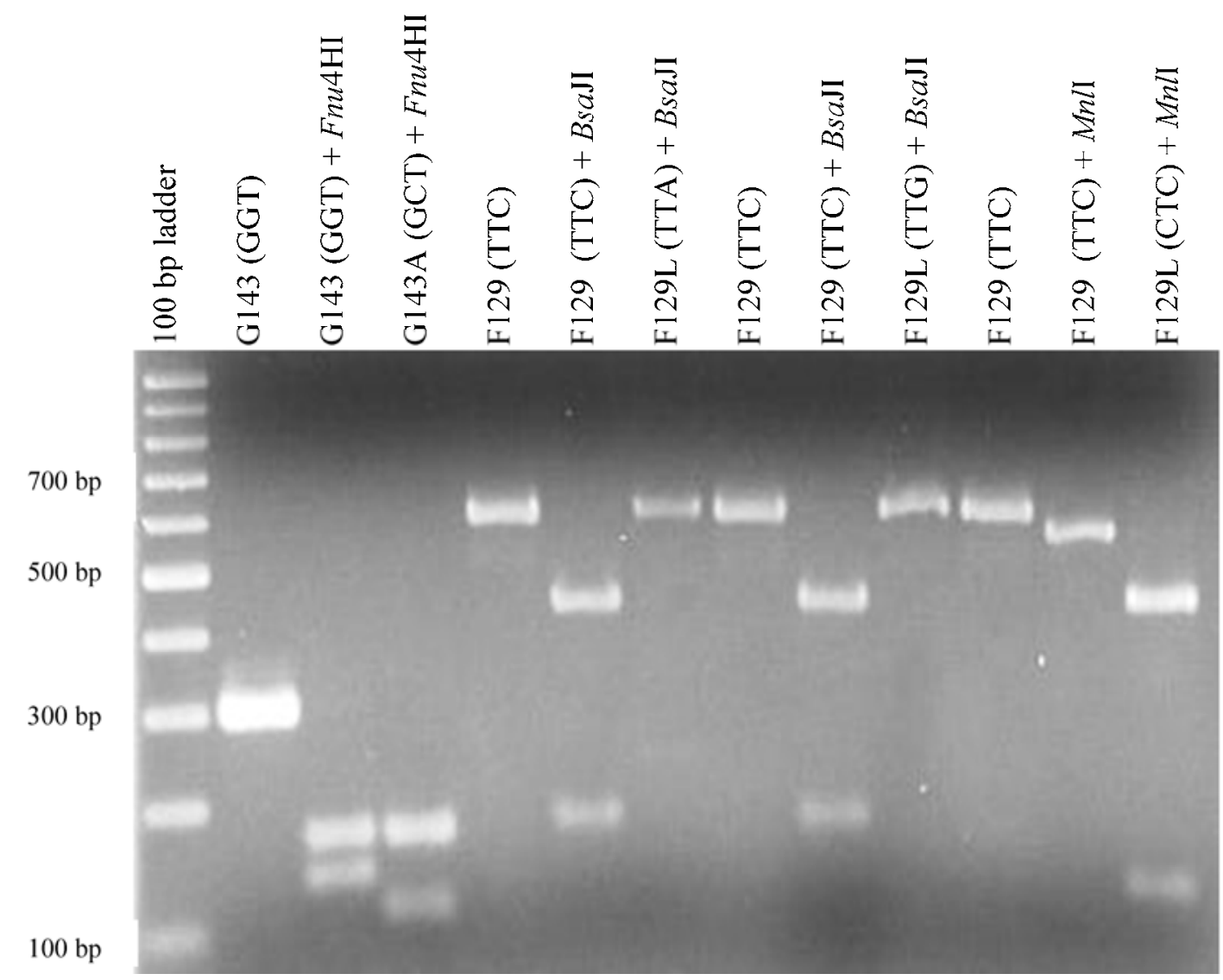

Fig. 1. Restriction digestion patterns from an amplified fragment of the cyt $b$ gene containing wild-type and mutant codons. G143 and F129 are wild-type DNA whereas G143A and F129L are the mutant type. Codons responsible for wild-type and mutant clones are described in parentheses. 

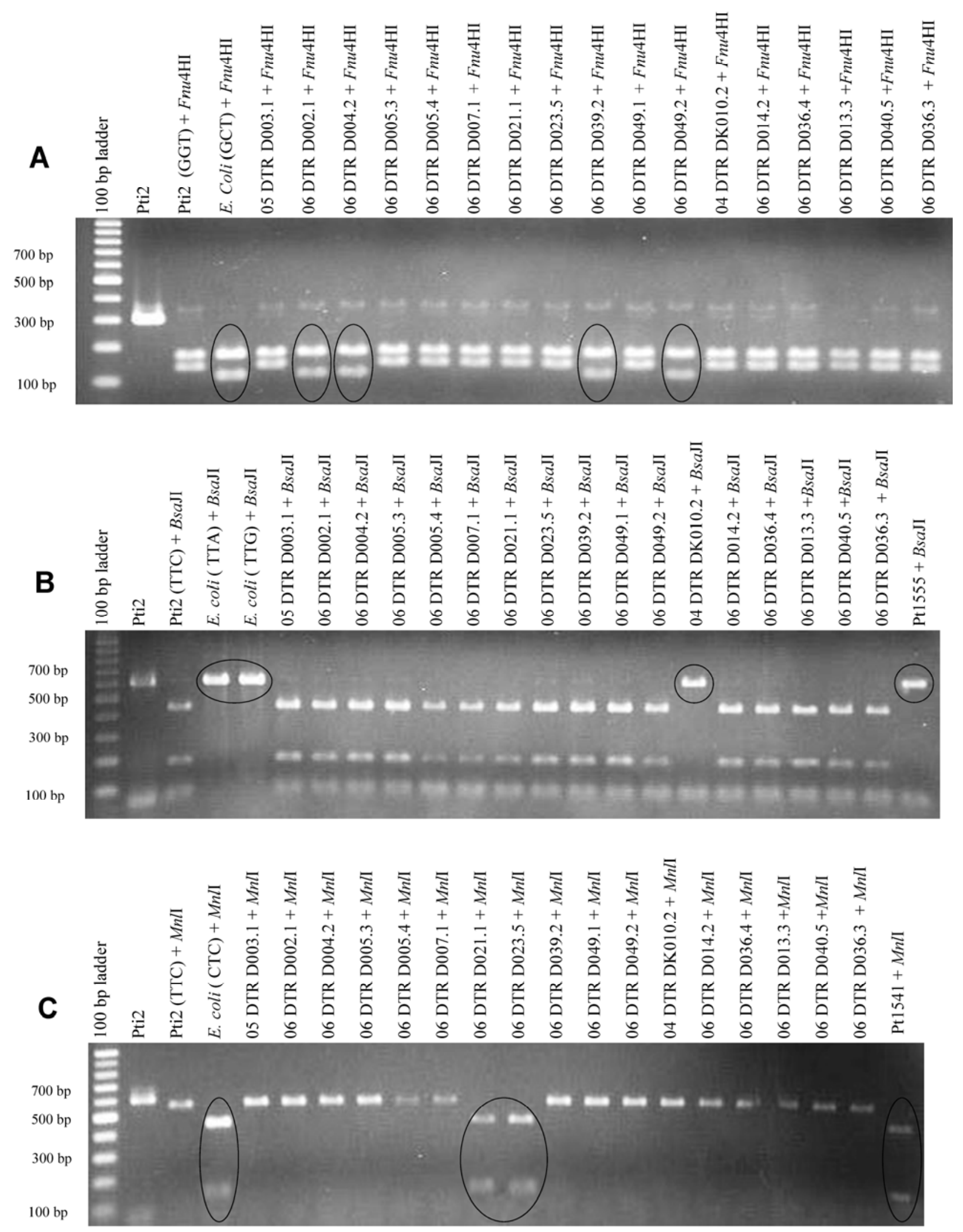

Fig. 2. DNA banding patterns of wild-type and mutant clones of Pyrenophora tritici-repentis and $P$. teres isolates digested with three restriction enzymes: $\mathbf{A}, F$ Fnu4HI; $\mathbf{B}, B s a J l ;$ and C, Mnll. Wild-type genomic DNA of the Pti2 isolate, mutant DNA sequence alone, and restriction enzyme-treated mutant DNA served as controls. Lane 1 represents $100-$ bp DNA ladder; lane 2, DNA of wild-type isolate without restriction enzyme treatment; lane 3, DNA of wild-type isolate of $P$. tritici-repentis treated with respective enzyme treatment; lane 4, restriction enzyme treated PCR amplified mutant type DNA from Escherichia coli plasmid with GCT codon (A) and CTC codon (C); lanes 4 and 5, restriction enzyme treated PCR amplified mutant type DNA from E. coli plasmid with TTA and TTG codon, respectively (B); lanes 5-21 (A and C) and lanes 6-22 (B), P. tritici-repentis isolates; lane 22, P. teres isolate with CTC codon at F129L (C); and lane 23, P. teres isolate with TTA codon at F129L (B). Circles around the DNA bands denote mutant type restriction digestion pattern. 
work has prompted us to develop specific primers to detect SNPs responsible for the shift in the sensitivity of $P$. tritici-repentis and P. teres to QoI fungicides. Although Sierotzki et al. (29) developed a SYBR green-based quantitative real-time PCR method, this assay is relatively expensive. In this study, we developed a cost-effective and rapid PCR-based system, which can be used by most diagnostic laboratories. Primers described previously (29) were not specific to $P$. tritici-repentis and $P$. teres because they were based on cyt $b$ sequence homologous to other ascomycetes. In addition, 12 primers were needed to amplify fragments of cyt $b$ region at G143A and F129L sites to distinguish wild-type and mutant sequences by sequence analysis (29). Compared with the previous real-time PCR method (29), the PCR method described here requires only one primer pair to amplify genomic regions at G143A of $P$. tritici-repentis and another primer pair to amplify genomic regions at F129L of $P$. tritici-repentis and $P$. teres. Importantly, these primer sets are specific to the amplified region of cyt $b$ gene at G143 and F129 site of the P. tritici-repentis.

A pyrosequencing method was used to monitor sensitivity of $M$. grisea isolates to orysastrobin (31). This one reaction approach was used to monitor G143A and F129L mutations; however, this method requires expensive equipment and sequencing reagents. Monitoring of F129L mutation in P. teres isolates has been also carried out using a pyrosequencing method $(27,32)$. Many other monitoring methods have been conducted using PCR-RFLP analysis to detect G143A and F129L mutations in different fungi $(4,18,30,35)$.

The primer sets used in this study were specific to a fragment of the cyt $b$ gene of $P$. tritici-repentis. We successfully created and cloned the mutants of two fragments of the cyt $b$ gene and used them as controls to test a PCR detection method. PCR protocols with specific primers also showed that this method is sensitive, allowing PCR-based detection of the mutations from DNA concentrations as low as $10 \mathrm{ng} / \mu \mathrm{l}$. We distinguished the wild-type codon GGT and the mutant codon GCT at G143A using Fnu4HI enzyme. The $M n l I$ restriction enzyme was used to distinguish the wild codon TTC from the mutant codon CTC at position F129L. Intriguingly, this method could not distinguish between the TTA and TTG changes; however, it could certainly recognize the presence of these codons, which are different from the wild-type DNA sequence. We selected one restriction enzyme (BsaJI), which could be used to detect differences between the wild type (TTC codon) and both the mutant TTA and TTG codons at F129.

The G143A mutation has not yet been found in P. teres isolates. It is likely due to the presence of an intron next to the G143 site (29). However, P. teres has $99 \%$ sequence similarity with the 584bp fragment of the cyt $b$ gene amplified from $P$. tritici-repentis in the F129 region. We took advantage of this to test known QoI-reduced-sensitive isolates of $P$. teres. The results showed that this method accurately identified known mutant TTA and CTC in the QoI-reduced-sensitive isolates of $P$. teres.

We also compared the results of the molecular detection assay for the same isolates of $P$. tritici-repentis with the previous in vitro sensitivity method (29). Although the data from both methods were consistent, our molecular approach detected four highly QoI-insensitive isolates (GCT codon at G143A) and -reduced-sensitive isolates (TTA or TTG and CTC at F129L) of P. tritici-repentis. We identified one isolate (06DTR D023.5) with the CTC codon which had high $\mathrm{EC}_{50}$ value $(100 \mathrm{mg} / \mathrm{liter})$ similar to the GCT codon in isolates of $P$. tritici-repentis. This high $\mathrm{EC}_{50}$ value may be due to the many mutated mitochondrial cyt $b$ genes at position F129L in a cell of $P$. tritici-repentis which collectively influence the sensitivity to the QoI fungicides. We could not identify two QoI-reducedsensitive isolates with elevated $\mathrm{EC}_{50}$ values: 06DTR D036.4 (azoxystrobin $\mathrm{EC}_{50}$ of $1.6 \mathrm{mg} / \mathrm{liter}$ ) and 06DTR D014.2 (azoxystrobin $\mathrm{EC}_{50}$ of $3.4 \mathrm{mg} / \mathrm{liter}$ ). These $P$. tritici-repentis isolates do not have the codon GCT at G143A or any of the three codons TTA, TTG, and CTC at F129L of the cyt $b$ gene. The isolate 06DTR D014.2 possessing the higher $\mathrm{EC}_{50}$ values has the codon AGG, which results in a change from glycine to arginine
(G137R) (29). In a preliminary screen of isolates collected in 2007 and 2009 from North Dakota, we could not find any with the G143A or F129L mutation using our molecular detection method (data not shown). The method described in this study can only detect four known mutations (codon GCT at G143A and codons TTA, TTG, and CTC at F129L). Any other possible mutations cannot be detected by this method.

In conclusion, we developed control mutant clones of the cyt $b$ gene containing the known codon changes responsible for a shift in the sensitivity to the QoI fungicides in $P$. tritici-repentis. Only two primer sets (primers FG143 and RG143 from Table 1 and primer FF129 and RF129 from Table 2) are needed to amplify a specific cyt $b$ region from isolates of $P$. tritici-repentis. $P$. tritici-repentis reproduces sexually once in a cropping season, with several asexual reproductive cycles in a cropping season (9). The mixed nature of this reproduction system may pose a high risk for QoI-resistance development, particularly when QoI fungicides are used consecutively for many years. Here, we developed a two-step detection method (PCR-based assay followed by restriction enzyme digestion) that could monitor four known mutations in QoI-insensitive and -reduced-sensitive isolates of $P$. tritici-repentis. This newly developed molecular detection method is rapid and specific and will be useful to complement conventional methods for monitoring QoI-insensitive and -reduced-sensitive field isolates of $P$. triticirepentis.

\section{Acknowledgments}

We thank R. Frey (Syngenta Crop Protection, Switzerland) and A. Koch (BASF, Germany) for providing valuable genomic DNA samples of P. triticirepentis and $P$. teres, respectively, to validate our molecular approach; and the Wheat Research and Promotion Council, Minnesota, North Dakota Wheat Commission, and State Board of Agricultural Research and Education, North Dakota for financial support for this project.

\section{Literature Cited}

1. Aljanabi, S. M., and Martinez, L. 1997. Universal and rapid salt extraction of high quality genomic DNA for PCR-based techniques. Nucleic Acids Res. 25:4692-4693.

2. Amiri, A., Brannen, P. M., and Schnabel, G. 2010. Reduced sensitivity in Monilinia fructicola field isolates from South Carolina and Georgia to respiration inhibitor fungicides. Plant Dis. 94:737-743.

3. Ammermann, E., Lorenz, G., Schelberger, K., Mueller, B., Kirstgen, R., and Sauter, H. 2001. BAS $500 \mathrm{~F}$ - the new broad-spectrum strobilurin fungicide. Pages 541-548 in: Brighton Crop Prot. Conf. Pests Dis. Vol. 2. Major Print, Nottingham, UK.

4. Araki, Y., Sugihara, M., Sawada, H., Fujimoto, H., and Masuko, M. 2005. Monitoring of the sensitivity of Magnaporthe grisea to metominostrobin 2001-2003: no emergence of resistant strains and no mutations at codon 143 or 129 of the cytochrome b gene. J. Pestic. Sci. 30:203-208.

5. Avila-Adame, C., Olaya, G., and Köller, W. 2003. Characterization of Colletotrichum graminicola isolates resistant to strobilurin-related QoI fungicides. Plant Dis. 87:1426-1432.

6. Banno, S., Ymashita, K., Fukumori, F., Okada, K., Uekusa, H., Takagaki, M., Kimura, M., and Fujimura, M. 2009. Characterization of QoI resistance in Botrytis cinerea and identification of two types of mitochondrial cyt $b$ gene. Plant Pathol. 58:120-129.

7. Bartlett, D. W., Clough, J. M., Godwin, J. R., Hall, A. A, Hamer, M., and Parr-Dobrzanski, B. 2002. The strobilurin fungicides. Pest Manage. Sci. 58:649-662.

8. Blixt, E., Djurle, A., Yuen, J., and Olson, A. 2009. Fungicide sensitivity in Swedish isolates of Phaeosphaeria nodorum. Plant Pathol. 58:655-664.

9. Ciuffetti, L. M., and Tuori, R. P. 1999. Advances in the characterization of the Pyrenophora tritici-repentis-wheat interaction. Phytopathology 89:444449.

10. Fungicide Resistance Action Committee. 2011. FRAC Code List: fungicides sorted by mode of action (including FRAC Code numbering) http://www.frac.info/frac/publication/anhang/FRAC\%20Code\%20List $\% 202$ 011-final.pdf.

11. Fungicide Resistance Action Committee. Revised January 2011. FRAC list of plant pathogenic organisms resistant to disease control agents. http://www.frac.info/frac/publication/anhang/List\%20of\%20resistant $\% 20 \mathrm{pl}$ ant\%20pathogens_Jan\%202011.pdf.

12. Gisi, U., Sierotzki, H., Cook, A., and NcCaffery, A. 2002. Mechanisms influencing the evolution of resistance to Qo inhibitor fungicides. Pest Manage. Sci. 58:859-867.

13. Ho, S. N., Hunt, H. D., Horton, R. M., Pullen, J. K., and Peasea, L. R. 1989. Site-directed mutagenesis by overlap extension using the polymerase chain reaction. Gene 77:51-59. 
14. Horton, R., and Pease, L. 1991. Recombination and mutagenesis of DNA sequences using PCR. Pages 217-247 in: Directed Mutagenesis: A Practical Approach. M. J. McPherson, ed. IRL Press, Oxford.

15. Ishi, H., Fraaije, B. A., and Sugiyama, T. 2001. Occurrence and molecular characterization of strobilurin resistance in cucumber powdery mildew and downy mildew. Phytopathology 91:1166-1171.

16. Kaku, K., Takagaki, M., Shimizu, T., and Nagayama, K. 2003. Diagnosis of dehydratase inhibitors in melanin biosynthesis inhibitor (MBI-D) resistance by primer-introduced restriction enzyme analysis in scytalone dehydratase gene of Magnaporthe grisea. Pest Manage. Sci. 59:843-846.

17. Kim, Y. S., Dixon, E. W., Vincelli, P., and Farman, M. L. 2003. Field resistance to strobilurin (QoI) fungicides in Pyricularia grisea caused by mutations in the mitochondrial cytochrome $b$ gene. Phytopathology 93:891-900.

18. Ma, Z., Felts, D., and Michailides, T. J. 2003 Resistance to azoxystrobin in Alternaria isolates from pistachio in California. Pestic. Biochem. Physiol. 77:66-74.

19. Ma, Z., and Michailides, T. J. 2005. Advances in understanding molecular mechanisms of fungicide resistance and molecular detection of resistant genotypes in phytopathogenic fungi. Crop Prot. 24:853-863.

20. Martin, L. A., and Fox, R. T. V. 1992. Use of polymerase chain reaction for the diagnosis of MBC resistance in Botrytis cinerea. Pages 207-214 in: Brighton Crop Prot. Conf. Pests Dis.

21. McKay, G. J., Egan, D., Morris, E., and Brown, A. E. 1998. Identification of benzimidazole resistance in Cladobotryum dendroides using a PCR-based method. Mycol. Res. 102:671-676.

22. Pasche, J. S., Piche, L. M., and Gudmestad, N. C. 2005. Effect of the F129L mutation in Alternaria solani on fungicides affecting mitochondrial respiration. Plant Dis. 89:269-278.

23. Pasche, J. S., Wharam, C. M., and Gudmestad, N. C. 2004. Shift in sensitivity of Alternaria solani in response to QoI fungicides. Plant Dis. 88:181187.

24. Ransom, J. K., Mergoum, M., and Simsek, S. 2010. North Dakota hard red spring wheat variety trial results for 2010 and selection guide. N. D. State Univ. Ext. Serv. A-574.

25. Rees, R. G., and Platz, G. J. 1983. Effects of yellow spot on wheat: comparison of epidemics at different stages of crop development. Aust. J.
Agric. Res. 34:39-46.

26. Sambrook, J., Fritsch, E. F., and Maniatis, T. 1989. Molecular Cloning: A Laboratory Manual, 2nd ed. Cold Spring Harbor Laboratory, Cold Spring Harbor, NY.

27. Semar, M., Strobel, D., Koch, A., Klappach, K., and Stammler, G. 2007. Field efficacy of pyraclostrobin against populations of Pyrenophora teres containing the F129L mutation in the cytochrome $b$ gene. J. Plant Dis. Prot. 114:117-119.

28. Shabber, A., and Bockus, W. W. 1988. Tan spot effects on yield and yield components relative to growth stage in winter wheat. Plant Dis. 72:599-602.

29. Sierotzki, H., Frey, R., Wullschleger, J., Palermo, S., Karli, S., Godwin, J., and Gisi, U. 2007. Cytochrome $b$ gene sequence and structure of Pyrenophora teres and $P$. tritici-repentis and implications for QoI resistance. Pest Manage. Sci. 63:225-233.

30. Sierotzki, H., Wullschleger, J., and Gisi, U. 2000. Point mutation in cytochrome $b$ gene conferring resistance to strobilurin fungicides in Erysiphe graminis f. sp. tritici isolates. Pestic. Biochem. Physiol. 68:194-201.

31. Stammler, G., Itoh, M., Hino, I., Wantanabe, A., Kojima, K., Motoyoshi, M., Koch, A., and Haden, E. 2007. Efficacy of orysastrobin against blast and sheath blight in transplanted rice. J. Pestic. Sci. 32:10-15.

32. Stammler, G., Strobel, D., Semar, M., and Klappach, K. 2006. Diagnostic of fungicide resistance and relevance of laboratory data for the field. Asp Appl. Biol. 78:29-36.

33. Stierl, R., Merk, M., Schrof, W., and Butterfield, E. J. 2000. Activity of the new BASF strobilurin fungicide, BAS 500F, against Septoria tritici on wheat. Brighton Crop Prot. Conf. Pests Dis. 3:859-864.

34. Vincelli, P., and Dixon, E. 2002. Resistance to QoI (Strobilurin-like) fungicides in isolates of Pyricularia grisea from perennial ryegrass. Plant Dis. 86:235-240.

35. Walker, A.-S., Auclair, C., Gredt, M., and Leroux, P. 2009. First occurrence of resistance to strobilurin fungicides in Microdochium nivale and Microdochium majus from French naturally infected wheat grains. Pest Manage. Sci. 65:906-915.

36. Wise, K. A., Bradley, C. A., Pasche, J. S., and Gudmestad, N. C. 2009. Resistance to QoI fungicides in Ascochyta rabiei from chickpea in the Northern Great Plains. Plant Dis. 93:528-536. 